\title{
A Technology-Assisted Design Methodology for Employee-Driven Innovation in Services
} Kentaro Watanabe, Ken Fukuda, and Takuichi Nishimura

\author{
"In management, the first concern of the company is the") \\ happiness of people who are connected with it. If the \\ people do not feel happy and cannot be made happy, \\ that company does not deserve to exist.
}

Kaoru Ishikawa (1915-1989)

Organizational theorist

\begin{abstract}
The role of employees is becoming more important in managing complex service processes and in serving the variety of customer needs in the service industry. Within efforts to promote innovation in service fields, employee-driven innovation and service design are gaining attention. Though the relationship between employee-driven innovation and service design has been discussed, the effectiveness of service-design methodologies for employeedriven innovation has not been studied sufficiently. In this article, we propose a technologyassisted design methodology to promote employee-driven innovation in services. Through our case study at an elderly-care facility, we confirmed that the proposed design methodology assisted by the communication support system could trigger employee-driven innovation and expand its influence in the service field.
\end{abstract}

\section{Introduction}

The increasing complexity of service processes and the increasing variety of customer needs in the service industry had highlighted the role of employees in promoting innovation. Employees in many service fields are required to respond to customers and other employees both flexibly and autonomously. Their skills and practical knowledge of services are highly important to service innovation. Thus, employee-driven innovation (Høyrup, 2010; Kesting \& Ulhøi, 2010) is expected to accelerate the improvement of productivity and quality of services.

The role of employees as a source of innovation is gaining attention not only in management science but also in other research fields, including design research. In addition to research from a management perspective, a service-design approach has strong potential to help employees promote innovation in the service industry. The relationship between employee-driven innovation and service design has been discussed(e.g., Hasu et al., 2011); however, the effectiveness of methodologies of service design for employee-driven innovation and their applicability to employees have not been studied sufficiently.
In this article, we explore a design methodology applicable to employees in service fields for triggering and promoting employee-driven innovation. Most of the existing methodologies in the service design literature are to be applied by professional designers. One of the promising approaches to realize an applicable design methodology for employees is the utilization of information technologies to enhance their capabilities to identify problems or opportunities in services and then represent and diffuse their innovation ideas. We propose a technology-assisted design methodology for employees and conduct a case study to clarify its effectiveness for employee-driven innovation.

This article is structured as follows. In the next section, we provide the theoretical background to this study through a description of existing research into employee-driven innovation and service design, including its technological support. Building on this background, we then propose a technology-assisted design methodology for employee-driven innovation and introduce a case study that illustrates the proposed methodology. Finally, we discuss the results of the case study and provide conclusions. 


\section{A Technology-Assisted Design Methodology for Employee-Driven Innovation in Services} Kentaro Watanabe, Ken Fukuda, and Takuichi Nishimura

\section{Theoretical Background}

Recently, it has been commonly noticed that company management is not limited to hierarchical and topdown processes. Particularly for innovation in services, the role of employees who are familiar with the needs of customers and problems in existing work practice is important. Within this context, employee-driven innovation (Høyrup, 2010; Kesting \& Ulhøi, 2010) is gaining attention in service industries. According to Kesting and Ulhøi (2010), employee-driven innovation is "the generation and implementation of significant new ideas, products, and processes originating from a single employee or the joint efforts of two or more employees who are not assigned to this task." Though the research on employee-driven innovation is rather new, the features and requisites for employee-driven innovation have been studied through various case studies of business organizations (Rocha, 2010; Teglborg-Lefèvre, 2010). In service industries, healthcare service contexts such as hospitals are common research objects (Telljohann, 2010; Castren \& Maijanen, 2013).

Employee-driven innovation can be discussed in relation to the existing theories and methodologies on improving, innovating, and designing practices in workplaces. For example, Høyrup $(2010,2012)$ highlighted the relevance of employee-driven innovation to organizational learning or workplace learning. Employees constantly attempt to adapt their work practices to the service situations they encounter; this learning process is considered fundamental for employee-driven innovation. And, this process can be considered as an opportunity to improve employability from the employees' perspective (Høyrup, 2010) and as a source of innovation from the management's perspective. Thus, the employees' ability to improve their workplace is a core driving force of employee-driven innovation. The innovation process by employees can be also explained in comparison with existing innovation forms such as "bricolage", an approach to managing problems using the existing resources at hand, and "ad hoc innovation", which refers to a solution to a particular problem posed by a particular client (Castren \& Maijanen, 2013; Fuglsang, 2011). These two types of innovations are essential for resource-restricted situations and contextspecific problems in service fields.

To promote employee-driven innovation, business managers could apply structured approaches such as an incentive system for employees (Teglborg-Lefèvre, 2010) and workshops to gather innovative ideas (Telljo- hann, 2010). In addition to these mechanisms, some researchers have studied the personal and cultural aspects of employee-driven innovation, such as how the agency of employees toward changing their work practices can affect activities in employee-driven innovation (Billett, 2012, Brandi \& Hasse, 2012).

Service design, on the other hand, has been studied as another trend for innovating services. Service design, or the design of services, has been discussed in various research contexts, such as design research, management, and engineering (Kimbell, 2011; Mager, 2008). Many service design studies take human-centred approaches (Stickdorn \& Schneider, 2012). The empathy for users in design thinking (Brown, 2009) is considered as an important element in service design and ethnographic approaches are commonly used to study the stakeholders of the target services. In addition, the recent studies on service design rely more on the active participation of employees based on approaches of participatory design and co-design (Sanders \& Stappers, 2008; Steen et al., 2011). Various co-design projects have been conducted, particularly in relation to healthcare services as seen in studies by Garde and van der Voort (2013) and by Steen and colleagues (2011).

Though both of these studies focus on employees as sources of innovation, their approaches have significant differences. First, a different major actor innovates the services in each case. Employee-driven innovation is a bottom-up innovation process by employees who operate services. Though the co-design approach with employees is now appreciated, professional designers still take a major role in service design. As another characteristic of service design research, the methodologies and tools to create and realize new ideas from the practitioners' viewpoints are central. For example, design approaches are more interested in the representation of concepts and ideas. There is a variety of representation forms, including service blueprinting (Shostack, 1984), a miniature of service environments (Garde \& van der Voort, 2013) and acting-out that is a kind of role-playing to simulate designed activities (Sunaga, 2009). Through continuous representation or prototyping, concepts of new services can be evaluated and refined (Stickdorn \& Schneider, 2012). These methodologies and tools are designed to support the activities of service designers, though they also facilitate the participation of employees in design. However, if these methodologies and tools were available for employees to redesign their own services, it would be an effective way to promote employee-driven innovation. 


\section{A Technology-Assisted Design Methodology for Employee-Driven Innovation in Services} Kentaro Watanabe, Ken Fukuda, and Takuichi Nishimura

\section{Observation and representation}

Two methodological approaches in service design are particularly relevant to the context of employee-driven innovation: observation and representation. In service design, external observation and analysis are commonly performed to understand stakeholders and related situations. Meanwhile, in the existing research on employee-driven innovation, reflection is considered as an important process to understand work practices and situations in service fields (Høyrup, 2010, 2012). However, employees' thoughts tend to be focused on their own roles and tasks, and it is not necessarily easy for them to understand the perspectives of stakeholders and related situations by reframing their mindsets compared to the design practice of external designers. Further assistance should be considered, especially for busy employees.

The other methodological approach of service design is representation. Especially in service design, continuous prototyping (or representation) and evaluation by users are considered as important processes (Stickdorn \& Schneider, 2012). How to externalize the ideas of employees is rarely discussed in the existing studies on employee-driven innovation, and addressing this challenge could be an important contribution of design research to employee-driven innovation. The externalized design ideas can be used to diffuse design results within the organization. Furthermore, it is unreasonable to expect all employees in service fields to be skilled in representation. Therefore, it is also important to know how to assist representation by employees in service fields.

\section{A Technology-Assisted Design Methodology}

In this study, we examine how to assist employees' design activities with information technologies. In the existing literature on employee-driven innovation, the methods and tools are considered to take an important role in promoting innovation activities by employees (Aasen et al., 2012). For example, there have been several case studies on the application of web-based technologies to collect innovation ideas (Teglborg-Lefèvre, 2010; Ackerman et al., 2013). However, few studies further explore technological assistance for employee-driven innovation beyond ways of sharing innovative ideas. Various technologies to support service design have been developed, for example, in the field of service engineering (AIST, 2008). Mobile technologies and ubiquitous technologies would be particularly effective in supporting employees within ordinary work settings in service fields (Frohberg et al., 2009; Kristoffersen \& Ljungberg, 1999). These new technologies have a strong potential to enhance the capability of employees for employee-driven innovation.

In this section, we propose a technology-assisted design methodology to enable employee-driven innovation. Figure 1 shows a conceptual sketch of the proposed design methodology. The methodology is based on an autonomous and continuous design approach to service processes and systems by the community of employees: the user-driven product/activity design (UPAD) approach (Watanabe \& Nishimura, 2013). The proposed methodology intends to concretize this design concept.

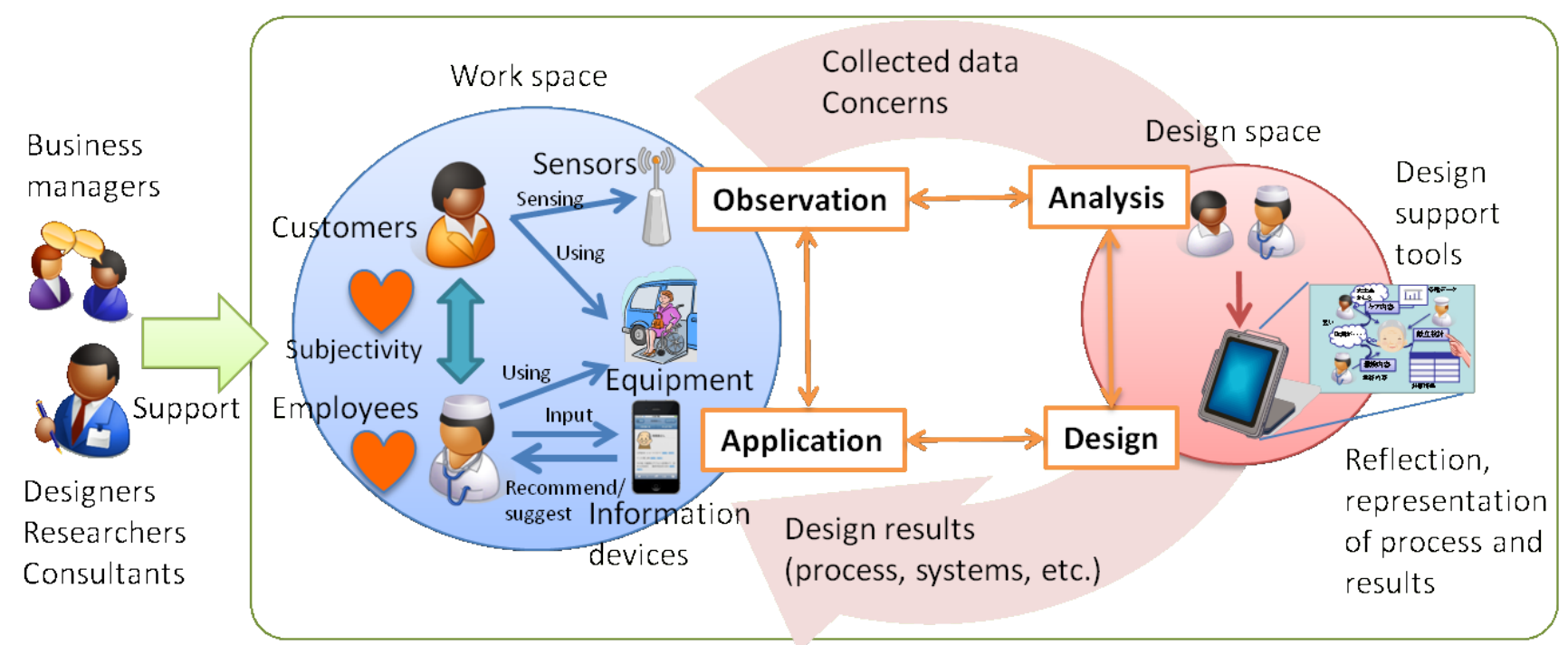

Figure 1. Conceptual sketch of the proposed design methodology 


\section{A Technology-Assisted Design Methodology for Employee-Driven Innovation in Services} Kentaro Watanabe, Ken Fukuda, and Takuichi Nishimura

In this design methodology, a community of employees performs design activities. These activities are supported by business managers and, if necessary, outsources such as designers and consultants, especially in the early stages.

In this design methodology, we define two types of spaces where employees are supported with technologies. The first space is the "work space": an ordinary work setting for employees, where actual service processes and encounters with customers are held. The second space is "design space": any kind of situation to reflect and redesign services by employees. Design space includes not only workshops or formal meetings set specifically for employee-driven innovation, but also informal meetings or even chats among employees relating to their specific concerns. These casual occasions arising from "in-line" activities (Høyrup, 2012) could create new findings and sources of innovation. Design spaces could emerge anytime and anywhere, and it is important to support design activities when and where they emerge.

Related to these spaces, concrete design activities are defined in this methodology. They are described as a design cycle with four phases: observation, analysis, design, and application. These phases are determined using the notation of the optimum design loop (AIST, 2008). As Figure 1 shows, these design phases are not necessarily a one-way process but they could proceed back and forth through the cycle.

\section{Observation}

Understanding the current status of a service is an important step in redesigning it. Observation is usually conducted by a third party, but in this methodology, employees themselves mainly observe their own service activities. Therefore, the observation in this methodology means self-observation by employees and mutual observation among employees.

To observe changing situations in a work space is not easy for employees. In addition to the complexity of services, the localized concerns of employees in their own tasks make it difficult to have an overview of their own services (Kesting \& Ulhøi, 2010). Technologies can be used to support the observation phase, including sensors and information devices. The obtained data become a source to understand stakeholders and situations in busy daily work. Meanwhile, the subjectivity of employees - such as their concerns, perspectives, and feelings - strongly affects the performance of ser- vices. To understand stakeholders amidst this subjectivity, the following analysis phase is important.

\section{Analysis}

For the deep understanding of services, reflection by employees takes an important role. Design spaces provide opportunities not only to reflect on their service practices individually but also to share their perspectives and information to understand the current services from multi-dimensional aspects. For this purpose, the group representation of services is effective. For example, a representation tool to gather employees' perspectives on concerned issues has been proposed (Watanabe et al., 2014). In addition, the observed data could work as potential sources to understand the situations in service fields. By applying the analytical method to these data, such as a statistical and timeseries analysis (Miwa et al., 2012), a new viewpoint could be provided that reveals new issues to be discussed.

\section{Design}

Based on the results of the analysis phase, employees discuss how to change services. The design objects could be service processes, jobs, team arrangement, and IT systems used in services. The representation of design objects by employees takes an important role in this design phase also. By representing required situations and how to realize them, employees can concretize their ideas. However, employees in service fields are not necessarily familiar with the representation methods of these design results.

To apply a support tool for employees to represent their services, its representation form should be flexible enough to express the employees' mental models (Watanabe et al., 2014). In addition, simple and instant representation is also important for its use by busy employees. By using this kind of tool, representation of concerned issues and design results can be stored. They can be used as a stock of practical knowledge in work spaces.

\section{Application}

Represented design results, such as new service processes, roles, and rules, should be disseminated to employees for their application in work spaces. This process has not been discussed sufficiently in the design research and the employee-driven innovation research. Given that the proposed methodology is conducted in an ordinary work setting, it should be straightforward to apply its results through the support 


\section{A Technology-Assisted Design Methodology for Employee-Driven Innovation in Services} Kentaro Watanabe, Ken Fukuda, and Takuichi Nishimura

of certain technologies. A communication support system using, for example, mobile devices can be used for the application of design results. An education system such as an e-learning system would be also a promising technology for this purpose. The applied design results are verified by using newly collected data in work spaces.

\section{Case Study: An Elderly-Care Facility}

Here, we illustrate the proposed methodology using a case study of Wakoen, a long-term care facility for elderly people. Located in Noto area of Japan, the facility contains three floors (work spaces) and 150 beds, and approximately 10 employees work on each floor. We have been conducting a co-design project with several employees to develop a mobile communication system for an elderly-care service provided by employees (Watanabe \& Nishimura, 2013). In this facility, various kinds of informal information for elderly care, such as requests from a resident's family, used to be shared with paper notebooks. This new communication system, named DANCE, was designed and developed for timely communication support to replace the notebooks. Figure 2 shows sample screenshots of DANCE. This project also aimed at realizing the UPAD approach (described earlier) to promote the employees' design activities relating to service processes and systems used in the facility (Watanabe \& Nishimura, 2013). We star- ted by facilitating a user community consisting of employees. After continuous prototyping through their active participation, DANCE was deployed and has been used in the facility in an official capacity since February, 2014. Instead of paper notebooks, the new system uses approximately 23 iPod Touch and iPad devices.

There are two main functions in the DANCE system (Nishimura et al., 2013). The first function of DANCE is to create and share handover information about the care of residents, such as texts, photos, and voice recordings. DANCE can recommend candidates of related message examples based on the stored messages. Users of DANCE can also search for the handover information of a particular person by choosing recommended keywords. After checking handover information, users can leave a message as a reply or as additional information with texts and photos. The second function is to check and edit "face sheets", which are used to record a number of requirements for care relating to a resident's health, diet, and equipment needs, or other care notes for specific circumstances.

After deploying the DANCE system, we analyzed the change of employees' activities according to the proposed methodology. In addition, we analyzed data in DANCE and shared it with several Wakoen employees in a workshop, which provided an opportunity for them to reflect and redesign their work.

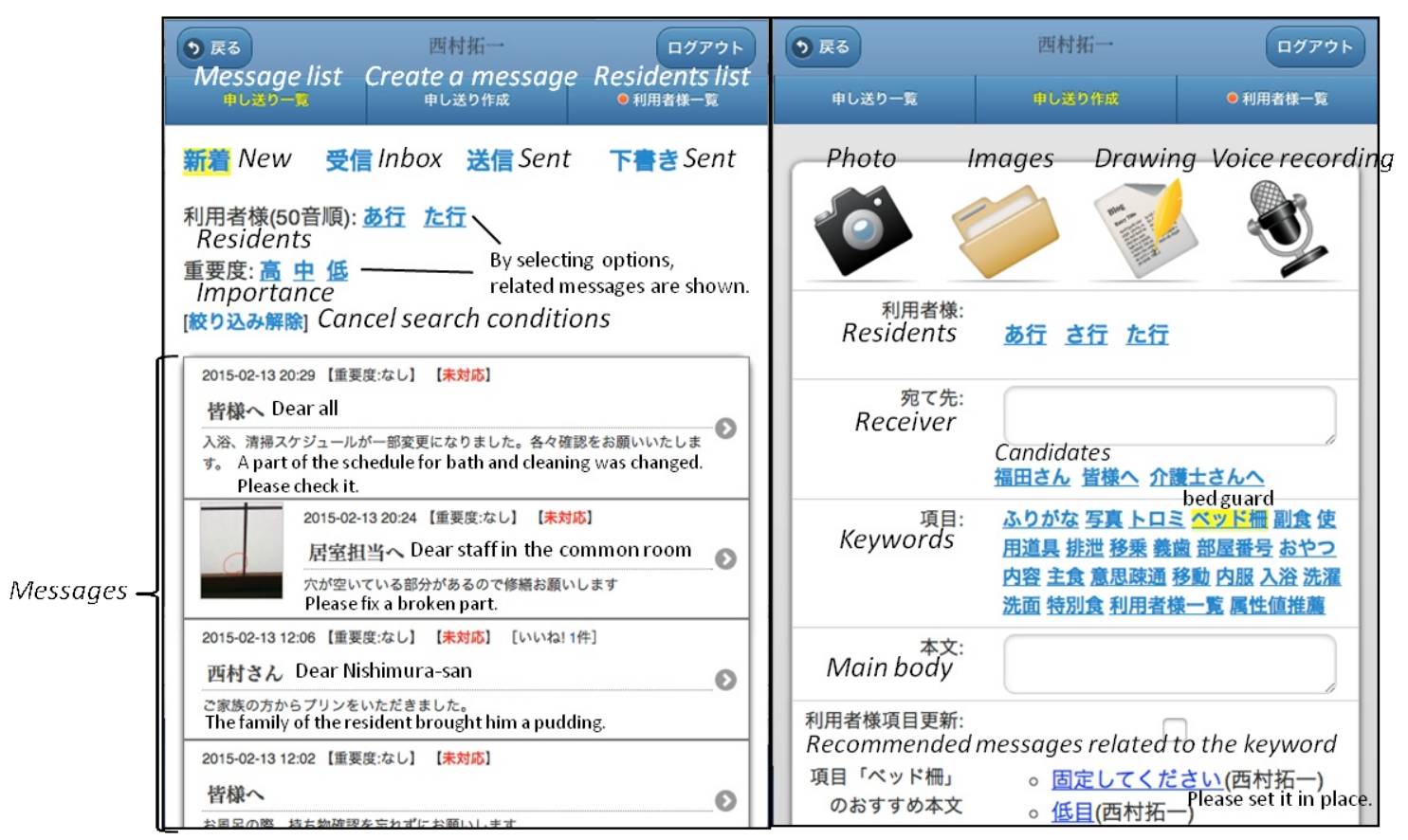

Figure 2. Screenshots of DANCE 


\section{A Technology-Assisted Design Methodology for Employee-Driven Innovation in Services} Kentaro Watanabe, Ken Fukuda, and Takuichi Nishimura

\section{Results}

Analysis of the design cycle using DANCE

DANCE is a communication medium for employees and it stores messages sent by them. These messages can be used to understand the current status of the service in the observation phase according to the proposed methodology. In addition, DANCE contains several functions for representation, such as the photo function. Thus, we wished to investigate how these functions may have been used in design activities also.

To confirm how DANCE was used in relation to the proposed design methodology, we conducted semistructured interviews with a manager and four members who participated in the design of DANCE. The interviews focused on the changes in service practices after the system was deployed. We also analysed how the photo function was used in the elderly-care facility. The data from DANCE used for the analysis was collected from May 1st to June 11th, 2014. Through these studies, we attempted to confirm how employees represent their ideas in the design phase and how DANCE was utilized for these purposes.

From the interviews with the employees, we obtained several remarks on how the proposed methodology and DANCE were utilized for employee-driven innovation. First, the photo function of DANCE changed the communication on service activities among the employees. Some of the employees used to add drawings to the notebook on how to care for certain residents. By using the photo function of DANCE, employees were able to better understand the situation and to more easily explain how to assist with eating and how to support the posture of a certain resident. This function encouraged them to share their ideas about innovating their services.

The shift from a notebook to a mobile device also changes the timings to check and input handover information. Nurses and physical therapists who work at several work spaces mentioned that it had become easier to check the situations in each work space in advance. They could not bring their devices with them during work - usually because of the limited number of devices. But, in comparison to the notebooks, which used to be located in each work space, employees were able to check messages more frequently.

As other remarks, the interviewees noted messages sent frequently with similar contents. This observation indicates that these messages should be emphasized to promote discussion. In addition, the DANCE system clarified which employees had read messages left for them. When they used notebooks, this was not recognized correctly. From the interviews, it was confirmed that a remaining challenge was how to let all of the employees read the messages.

The interview results showed that the photo function was used mainly for design and application of service activities. The analysis of photos in DANCE revealed that employees wrote down work processes or how to care for a specific resident on a piece of paper, which they then photographed and sent to the other employees. For example, one worker used this method to send handover information on how to take a resident to a bathroom for several occasions (daytime and night time). To indicate important points about care, employees also used an additional drawing function on photos, which allowed them to show, for example, how to set a pillow on a bed for the comfort of the resident. From these examples, we observed that the design results of service activities were effectively represented and shared among employees.

\section{Workshop based on the analysis of DANCE data}

DANCE does not contain the analysis method of obtained data. Therefore, it is difficult to obtain findings on the analysis phase through interviews and analysis of the photo function. Thus, to clarify the effectiveness of data analysis, we conducted a workshop with several employees in which we showed them the results of the co-occurrence network analysis performed on DANCE data of residents about whom workers frequently commented using the system. The co-occurrence network analysis identifies frequently used words and their relationships, which are then visualized in a graphical form. The results enabled the employees to reflect upon and redesign their work.

The participants in the workshop focused on major words in the co-occurrence network, such as: "visit", "husband", "eat", and "without notifying". These keywords reminded them of messages sent frequently in relation to a particular resident, such as: "the husband helped her eat without notifying care workers". This resident had difficulty in swallowing and needed assistance from care staff when eating. However, her husband helped her eat without notifying care staff, which could increase the risk of incidents, such as choking.

After the discussion among employees with different roles, they decided to allow her husband to help his wife eat, but only in the dining room. To prevent an incident, 


\section{A Technology-Assisted Design Methodology for Employee-Driven Innovation in Services} Kentaro Watanabe, Ken Fukuda, and Takuichi Nishimura

they designed their care work to adjust the posture of the resident before eating and to tell her husband not to bring other food such as snacks. The DANCE system was used to send this result to every employee. After this change, no further messages related to this issue were sent.

\section{Discussion}

In this article, we propose a design methodology with four phases to promote employee-driven innovation. The observation phase in this case study was related to collected data on service situations and operations with DANCE. These data were continuously accumulated and utilized in the analysis phase. In the workshop, the co-occurrence network analysis was able to visualize the issues to be discussed, and the extracted keywords were able to remind employees of the problems in their services. This empirical result highlights the effectiveness of technological analysis in creating an opportunity to reflect on service practices, and as a result, to trigger employee-driven innovation.

In the design phase, the employees represented a number of design results to innovate their work processes. These results were developed not only in the workshop but also during the ordinary work. This point illustrates a feature of the design space: it can emerge anytime and anywhere. In addition, many of these design results were based on the existing resources of employees and therefore can be considered as examples of bricolage (Fuglsang, 2011). We also found that using photos is effective as a means of representation for those who are not accustomed to visual representation. More importantly, the representation results were immediately sent to every employee. This application phase was sufficiently supported by DANCE. The handover information was shared more frequently with DANCE according to the interview results relating to the ease of access to information. This finding shows the effectiveness of adopting the representation method of service design and the communication support among employees. The employees were able to show their innovation ideas to other employees, which could promote employee-driven innovation in the service field.

These results indicated that the proposed four phases of the design methodology could be performed with the support of information technologies. It was also confirmed that the analysed data from information technologies (DANCE, in this case study) could trigger employee-driven innovation. In addition, the influence of employee-driven innovation could be increased with the representation method and the communication support system by diffusing innovation ideas in service fields.

The case study illustrates the applicability of the proposed design methodology to the actual service. In addition, we identified several practical implications. First, the adaptation of information technologies would require time and effort. From the interview results, the DANCE system clarified that some employees had not used it effectively. Meanwhile, it becomes possible to know how many people actually use information technologies for employee-driven innovation. Based on these data, adaptations to these technologies can be considered.

It should be also noted that this case study was conducted after the long-term co-design project. Thus, the employees already have sufficient motivations to utilize DANCE in their work. Although the proposed methodology and DANCE are effective in illustrating required activities and in assisting employee-driven innovation, there remains the important question of how to develop a creative culture and motivate employees. The visualization of current situations in service fields, as was performed in this case study, may be one promising approach.

In this case study, we only used DANCE as a data source for observation and analysis. Further studies are required to investigate the influence of using different kinds of technologies, such as sensing devices. Here, DANCE was applied as a replacement for existing media, so there were few adverse effects. But, in other situations where technologies are introduced to collect new data from the service field, the range of application and access to these data should be designed adequately. This issue should be considered in future research. In addition, the proposed methodology should be applied to other service fields to confirm its versatility.

\section{Conclusion}

In this article, we explored how employee-driven innovation could be triggered and promoted with the methodology of service design and related technologies. We first introduced the theoretical background of employee-driven innovation and service design, which we then used as the basis for proposing a technology-assisted design methodology to trigger and promote em- 


\section{A Technology-Assisted Design Methodology for Employee-Driven Innovation in Services} Kentaro Watanabe, Ken Fukuda, and Takuichi Nishimura

ployee-driven innovation. This methodology includes four design phases: observation, analysis, design, and application, and it requires information technologies for each phase.

To clarify how the proposed methodology trigger and promote EDI, we conducted a case study at an elderlycare facility. From the results of interviews with the employees, the data analysis of the communication support system, and the workshop to redesign services, we confirmed that the proposed methodology triggered employee-driven innovation and the designed innovation ideas were diffused in the service field with the support of the communication support system and its representation function. In future works, we intend to conduct further case studies with other kinds of technologies to promote innovation in service industries.

\section{Acknowledgements}

We appreciate Wakoen's sincere support for this study.

An earlier version of this article was presented at the 2014 Annual Conference of the European Association for Research on Services (RESER), which was held from September 11th to 13th in Helsinki, Finland. RESER is a network of research groups and individuals active in services research and policy formulation.

\section{References}

Ackerman, M. S., Dachtera, J., Pipek, V., \& Wulf, V. 2013. Sharing Knowledge and Expertise: The CSCW View of Knowledge Management. Computer Supported Cooperative Work, 22(4-6): 531-573.

http://dx.doi.org/10.1007/s10606-013-9192-8

AIST. 2008. Website of the Center for Service Research. National Institute of Advanced Industrial Science and Technology (AIST). Accessed August 8, 2014:

http://unit.aist.go.jp/cfsr/en/contents/introduction/

Aasen, T. M., Amundsen, O., Gressgård, L. J., \& Hansen, K. 2012. In Search of Best Practices for Employee-Driven Innovation: Experiences from Norwegian Work Life. In S. Høyrup, C. Hasse, M. Bonnafous-Boucher, K. Møller, \& M. Lotz (Eds.), Employee-Driven Innovation: A New Approach: 57-74. Basingstoke: Palgrave Macmillan.

http://dx.doi.org/10.1057/9781137014764.0011

\section{About the Authors}

Kentaro Watanabe is a Research Scientist in Center for Service Research at the National Institute of Advanced Industrial Science and Technology (AIST) in Japan. He holds a $\mathrm{PhD}$ in Engineering from the Graduate School of System Design at Tokyo Metropolitan University. His research interests includes design theory and methodology of products/services, service process analysis, service engineering, and product-service systems.

Ken Fukuda is a Senior Research Scientist in the Center for Service Research at the National Institute of Advanced Industrial Science and Technology (AIST) in Japan. He holds a PhD in Information Science from the University of Tokyo in Japan, and he has held visiting positions at the University of Tokyo and Waseda University. He specializes in knowledge engineering, text mining, natural language processing, and the semantic web, with particular interests in healthcare, smart cities, open government, and social computing.

Takuichi Nishimura is a Team Leader of the Service Process Modeling Research Team in the Center for Service Research at the National Institute of Advanced Industrial Science and Technology (AIST) in Japan. He holds a $\mathrm{PhD}$ in Engineering from the Graduate School of Engineering at Osaka University in Japan. His research interests include healthcare services, computer-supported cooperative work, service process analysis, and service engineering.

Billett, S. 2012. Explaining Innovation at Work: A Socio-Personal Account. In S. Høyrup, C. Hasse, M. Bonnafous-Boucher, K. Møller, \& M. Lotz (Eds.), Employee-Driven Innovation: A New Approach: 92-107. Basingstoke: Palgrave Macmillan.

http://dx.doi.org/10.1057/9781137014764.0014

Brandi, U., \& Hasse, C. 2012. Employee-Driven Innovation and Practice-Based Learning in Organizational Cultures. In S. Høyrup, C. Hasse, M. Bonnafous-Boucher, K. Møller, \& M. Lotz (Eds.), Employee-Driven Innovation: A New Approach: 127-148. Basingstoke: Palgrave Macmillan. http://dx.doi.org/10.1057/9781137014764.0016

Brown, T. 2009. Change by Design: How Design Thinking Transforms Organizations and Inspires Innovation. New York NY: Harper Business.

Castren, L., \& Maijanen, S. 2013. Understanding Employee-Driven Innovation: "Ad Hoc Innovations" and "Bricolage". Proceedings of the XXIII International RESER Conference, Aix-en-Provence, September 19-21, 2013. 


\section{A Technology-Assisted Design Methodology for Employee-Driven Innovation in Services} Kentaro Watanabe, Ken Fukuda, and Takuichi Nishimura

Frohberg, D., Göth, C., \& Schwabe, G. 2009. Mobile Learning Projects A Critical Analysis of the State of the Art. Journal of Computer Assisted Learning, 25(4): 307-331.

http://dx.doi.org/10.1111/j.1365-2729.2009.00315.x

Fuglsang, L. 2011. Bricolage as a Way to Make Use of Input from Users. In J. Sundbo \& M. Toivonen (Eds.), User-Based Innovation in Services: 25-44. Cheltenham: Edward Elgar Publishing. http://dx.doi.org/10.4337/9780857931962.00010

Garde, J. A., \& van der Voort, M. C. 2013. The Activity-Flow Co-Design Game: Designing for Scheduled and Unscheduled Use Situations. Proceedings of the Fifth International Congress of International Association of Societies of Design Research (IASDR2013), Tokyo, August 26-30, 2013.

Hasu, M., Saari, E., \& Mattelmäki, T. 2011. Bringing the Employee Back In: Integrating User-Driven and Employee-Driven Innovation in the Public Sector. In J. Sundbo \& M. Toivonen (Eds.), User-Based Innovation in Services: 251-278. Cheltenham: Edward Elgar Publishing.

http://dx.doi.org/10.4337/9780857931962.00010

Høyrup, S. 2010. Employee-Driven Innovation and Workplace Learning: Basic Concepts, Approaches and Themes. Transfer: European Review of Labour and Research, 16(2): 143-154. http://dx.doi.org/10.1177/1024258910364102

Høyrup, S. 2012. Employee-Driven Innovation: A New Phenomenon, Concept and Mode of Innovation. In S. Høyrup, C. Hasse, M. Bonnafous-Boucher, K. Møller, \& M. Lotz (Eds.), Employee-Driven Innovation: A New Approach: 3-33. Basingstoke: Palgrave Macmillan.

http://dx.doi.org/10.1057/9781137014764.0009

Kesting, P., \& Ulhøi, J. P. 2010. Employee-Driven Innovation: Extending the License to Foster Innovation. Management Decision, 48(1): 65-84.

http://dx.doi.org/10.1108/00251741011014463

Kimbell, L. 2011. Designing for Service as One Way of Designing Services. International Journal of Design, 5(2): 41-52.

Kristoffersen, S., \& Ljungberg, F. 1999. "Making place" to Make IT Work: Empirical Explorations of HCI for Mobile CSCW. Proceedings of the International ACM SIGGROUP Conference on Supporting Group Work: 276-285, Pheonix, AZ, November 14-17, 1999.

Mager, B. 2008. Service Design. In M. Erlhoff \& T. Marshall (Eds.), Design Dictionary: Perspectives on Design Terminology: 354-357. Basel: Birkhäuser.

http://dx.doi.org/10.1007/978-3-7643-8140-0_244

Miwa, H., Fukuhara, T., \& Nishimura, T. 2012. Service Process Visualization in Nursing-Care Service Using State Transition Model. In L. E. Freund (Ed.), Advances in the Human Side of Service Engineering: 3-12. Boca Raton, FL: CRC Press.
Nishimura, T., Fukuhara, T., Yamada, K., Hamazaki, M., Nakajima, M., Miwa, H., Watanabe, K., Fukuda, K., \& Motomura, Y. 2013. Proposal of Handover System for Care-Workers Using Community Intelligence. In M. Mochimaru, K. Ueda, \& T. Takenaka (Eds), Serviceology for Services - Selected Papers of the 1st International Conference of Serviceology Part V: 135-142. Tokyo: Springer Japan.

http://dx.doi.org/10.1007/978-4-431-54816-4_15

Rocha, R. S. 2010. Shop Stewards as Coordinators of EmployeeDriven Innovation: Implications for Trade Unions. Transfer: European Review of Labour and Research, 16(2): 185-196. http://dx.doi.org/10.1177/1024258910364306

Sanders, E. B. N., \& Stappers, P. J. 2008. Co-Creation and the New Landscapes of Design. CoDesign: International Journal of CoCreation in Design and the Arts, 4(1): 5-18.

http://dx.doi.org/10.1080/15710880701875068

Stickdorn, M., \& Schneider, J. 2012. This Is Service Design Thinking: Basics, Tools, Cases. Hoboken NJ: Wiley.

Sunaga, T. 2009. Information Design Theories, Methodologies and Practices: A Project on a Platform Design for People Art. Proceedings of International Conference on Interaction Design 2008, Beijing, October 16-18, 2008.

Steen, M., Manschot, M., \& De Koning, N. 2011. Benefits of CoDesign in Service Design Projects. International Journal of Design, 5(2): 53-60.

Teglborg-Lefèvre, A. C. 2010. Modes of Approach to EmployeeDriven Innovation in France: An Empirical Study. Transfer: European Review of Labour and Research, 16(2): 211-226. http://dx.doi.org/10.1177/1024258910364319

Telljohann, V. 2010. Employee-Driven Innovation in the Context of Italian industrial Relations: The Case of a Public Hospital. Transfer: European Review of Labour and Research, 16(2): 227-241.

http://dx.doi.org/10.1177/1024258910364308

Watanabe, K., \& Nishimura, T. 2013. A Unified Approach for Systematic and Participatory Design. Proceedings of the 19th International Conference on Engineering Design (ICED2013), Seoul, August 19-21, 2013.

Watanabe, K., Fujimitsu, S., Harada, Y., Niino, Y., Kobayakawa, M., Yamada, K., Sunaga, T., Sakamoto, Y., Nishimura, T., \& Motomura, Y. 2014. Proposal of a Design Support Tool for Employees to Represent Services Proceedings of the DESIGN 2014 13th International Design Conference: 1219-1228, Dubrovnik, May $19-22,2014$ 